\title{
AVALIAÇÃO DE INTERVENÇÕES EM UNIDADES DE APLICAÇÃO LOCALIZADA DE FERTILIZANTES E DE POPULAÇÕES DE MILHO
}

\author{
JOSÉ P. MOLIN ${ }^{1}$, LEONARDO S. MASCARIN ${ }^{2}$, PEDRO A. VIEIRA JÚNIOR ${ }^{3}$
}

\begin{abstract}
RESUMO: A agricultura de precisão busca gerenciar os recursos disponíveis, enfatizando o aumento na produtividade e mantendo ou reduzindo a quantidade de insumos. Entre as técnicas para a aplicação em taxa variável, está aquela baseada na recomendação de um insumo em função da variabilidade espacial da oferta ambiental. O objetivo deste trabalho é avaliar a metodologia e analisar a viabilidade do uso de unidades de aplicação, variando a população de plantas de milho e a dose de fertilizante formulado na operação de semeadura, comparando a aplicação em taxa fixa e em taxa variável em relação à produtividade de grãos e ao total de insumos gastos. Foram realizados três experimentos: em dois deles, as doses de fertilizante formulado NPK foram aplicadas em taxas variadas envolvendo largura de faixas com metodologias diferenciadas e, no outro, variando a população de plantas de milho. Os resultados obtidos mostraram que a metodologia com a utilização de faixas largas intercaladas é mais prática do que com faixas da largura da semeadura, e que o controlador de dosagem deve ser conectado a um receptor de GPS para a variação automática da dosagem. Além disso, a aplicação de fertilizante formulado NPK, considerando apenas um nutriente, causou desequilíbrios nutricionais, afetando o desenvolvimento da cultura.
\end{abstract}

PALAVRAS-CHAVE: agricultura de precisão, unidades de gerenciamento, aplicação de insumos a taxa variada.

\section{EVALUATION OF INTERVENTIONS ON MANAGEMENT ZONES FOR FERTILIZER AND CORN POPULATION}

\begin{abstract}
The use of precision agriculture tools implies on managing resources aiming to improve yield with the same amount or with reduction on inputs. Among the techniques for variable rate application, one is based on the spatial variability of available nutrients in the soil. The objective of this research is to adapt and test a methodology to evaluate the usefulness of application zones for fertilizer and seed rates for corn, done with a planter properly equipped and test it against a fix rate in terms of yield improvement and input savings. Three experiments were conducted. In two of them the rate of a NPK formula was applied with different strip width methodologies and in the third experiment the seed rate was varied. Results demonstrated that the use of wide strips is more practical than plancter width strips and controllers have to be connected to a GPS receiver for automatic rate changes. Also, the application of NPK formulas, considering just one element for recommendation caused nutritional unbalances to the crop.
\end{abstract}

KEYWORDS: precision agriculture, zone management, variable rate technology.

\section{INTRODUÇÃO}

A adoção de técnicas de agricultura de precisão destaca-se entre os agricultores que visam a otimizar os recursos disponíveis, enfatizando o aumento de produtividade e mantendo ou reduzindo o total de insumos (BLACKMORE, 1994), pois, ao se considerar a variabilidade espacial dos fatores de produção, é possível aplicar as quantidades necessárias em cada ponto, fortalecendo os conceitos de agricultura sustentável (GOERING \& HANS, 1993). A mesma tecnologia que permite a aplicação de insumos em taxa variada, pode ser utilizada para a população de plantas

\footnotetext{
${ }^{1}$ Engo Agrícola, Professor, ESALQ/USP, Piracicaba - SP, Fone (0XX19) 3429. 4165, jpmolin@ esalq.usp.br

${ }^{2}$ Eng $^{\mathrm{O}}$ Agrônomo, Mestrando em Máquinas Agrícolas, ESALQ/USP, Piracicaba - SP.

${ }^{3}$ Pesquisador, M.Sc., Embrapa Sete Lagoas, Doutorando em Fitotecnia, ESALQ/USP, Piracicaba - SP.

Recebido pelo Conselho Editorial em: 19-1-2006

Aprovado pelo Conselho Editorial em: 19-7-2006
} 
(CAMBOURIS et al., 2002). Variar a população de plantas é um conceito retomado com o surgimento dos recursos de GNSS (LOWENBERG-DEBOER, 1998).

Na cultura do milho, a produtividade de grãos aumenta linearmente com a população de plantas até um máximo denominado "ponto crítico", acima do qual a produção por planta decresce, enquanto a produção por área apresenta comportamento quadrático, possuindo ponto de máxima produção por unidade de área (DOURADO NETO et al., 2001). SHANAHAN et al. (2000) observaram que a produtividade respondeu previsivelmente com a variação da população de plantas de milho, sendo as populações determinadas com base nas produtividades anteriores.

A aplicação localizada de insumos é possível pela demarcação de unidades de gerenciamento que representem uma combinação homogênea de fatores limitantes da produtividade (FRIDGEN et al., 2000). As unidades de gerenciamento podem ser delineadas por amostragens e técnicas estatísticas (STEWART \& MCBRATNEY, 2000), ou por modelos considerando aspectos pedológicos, geomorfológicos, hidrológicos e ecológicos, descrevendo processos contínuos entre o sistema solo e os ambientes circunvizinhos (SÁ, 2001).

A utilização de mapas de aplicação de insumos com doses diferenciadas a partir de amostragem intensa e georreferenciada de solo é outra opção dinâmica temporalmente. Existe a possibilidade da simplificação da informação, representada pelo mapa de doses variadas, demarcando-se regiões que receberão doses uniformes, as quais podem ser referidas como unidades de aplicação para não se confundir com as unidades permanentes de gerenciamento. $\mathrm{O}$ controle da aplicação dos insumos é feito por dispositivos responsáveis pela variação da vazão, montados em equipamentos especializados para aplicação, principalmente de produtos sólidos, ou mesmo em semeadoras-adubadoras, e normalmente acionados por potência hidráulica. Para o caso de mapas com base em unidades de gerenciamento ou mesmo unidades de aplicação, a presença do controle automatizado não é obrigatória, pois as vazões de insumo serão alteradas apenas na transição entre unidades.

Considerando a necessidade de orientações para a aplicação de insumos em taxa variada, este trabalho teve como objetivo explorar a metodologia e analisar a viabilidade do uso de unidades de aplicação com tratamento diferenciado de população de plantas de milho e de doses de fertilizante formulado na operação de semeadura. Propõe-se, assim, comparar a aplicação em taxa fixa com aquela em taxa variável de fertilizante e semente em relação à produtividade de grãos e ao total de insumos utilizado nas áreas.

\section{MATERIAL E MÉTODOS}

O trabalho foi realizado na Fazenda Velha Lagoa, município de Campos Novos Paulista-SP, e constou de três experimentos (A, B, C) utilizando-se de talhões distintos com 71,3; 16,0 e 18,2 hectares, respectivamente. Os três experimentos foram semeados entre os dias 4 e 10-11-2003, com o híbrido de milho AG 9010, em sistema de semeadura direta sem irrigação, utilizando-se de duas semeadoras-adubadoras modelo COP Suprema (TATU Marchesan ${ }^{\circledR}$ ), com dez linhas espaçadas de $0,5 \mathrm{~m}$. Uma das máquinas foi equipada com controlador da variação das doses de fertilizante e de semente, enquanto a outra foi utilizada com os dois insumos em doses fixas. O controlador (Verion ${ }^{\circledR}$ ), adequado para unidades de aplicação, possibilitava a variação de quatro doses distintas de fertilizante ou de semente pela alteração da rotação dos motores hidráulicos, acionadores dos mecanismos dosadores da semeadora-adubadora, sendo as mudanças realizadas por botões localizados no monitor.

Para caracterizar a condição de disponibilidade de nutrientes no solo do experimento A, adotou-se grade amostral regular de uma amostra para três hectares, enquanto para os experimentos B e C a grade foi de uma amostra por hectare. Com os resultados das análises, interpolados pelo método de krigagem com uso do programa de SIG SSToolbox (SST Developmnet Group®), elaboraram-se os mapas de recomendação de adubação e população de plantas. Para a navegação durante a coleta das amostras e a demarcação das unidades de aplicação, utilizou-se um receptor de DGPS OminStar (Fugroß) com correção diferencial via satélite, conectado a um computador de 
mão (iPAQ Compaq®) provido do programa de navegação FarmSiteMate (Farm Works Software $\left.{ }^{\circledR}\right)$.

As doses de fertilizante foram estimadas com base no resultado da análise de solo e no teor contido no fertilizante, seguindo recomendações de IAC (1997). Optou-se pela determinação da dose do fertilizante com base nos requerimentos em fósforo, pois, embora as exigências do milho em fósforo sejam inferiores às de nitrogênio e de potássio, as doses recomendadas são altas em função da sua alta capacidade de fixação pelas partículas do solo (COELHO \& FRANÇA, 1995).

$\mathrm{O}$ experimento A foi desenvolvido em faixas de $150 \mathrm{~m}$ de largura, alternadas com o tratamento de adubação em dose fixa e outras em dose variada da fórmula 08-20-20, dentro das unidades de aplicação. A dose fixa foi de $330 \mathrm{~kg} \mathrm{ha}^{-1}$ do adubo formulado, conforme prática adotada na fazenda. As doses variadas, segundo a demanda em fósforo, foram de 200; 260; 330 e $380 \mathrm{~kg} \mathrm{ha}^{-1}$ do adubo.

Nos outros dois experimentos (B e C), foi realizada a operação de semeadura com as duas semeadoras trabalhando lado a lado, de modo a estabelecer faixas paralelas comparativas com a mesma largura da semeadora e, conseqüentemente, também da plataforma da colhedora. No experimento $\mathrm{B}$, também foram adotadas quatro unidades de aplicação com diferentes doses de fertilizante $\left(293 ; 330 ; 366\right.$ e $\left.403 \mathrm{~kg} \mathrm{ha}^{-1}\right)$ da mesma fórmula, seguindo a demanda de fósforo, além da dose fixa de $330 \mathrm{~kg} \mathrm{ha}^{-1}$.

No experimento $\mathrm{C}$, foi realizada uma avaliação de unidades de aplicação utilizando distintas populações de plantas de milho. As populações utilizadas foram estabelecidas a partir da análise de dados de produtividade dos dois ciclos anteriores da cultura do milho na área, adotando-se

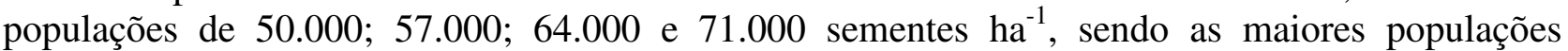
estabelecidas nos setores de maior produtividade histórica de grãos. Para a população fixa, foi

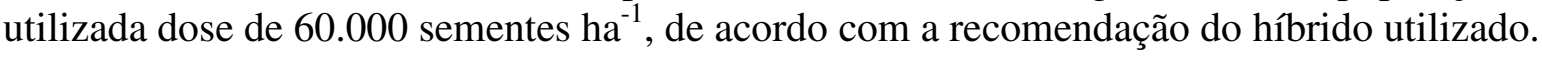

As colheitas foram realizadas entre os dias 17-2-2004 e 22-2-2004 utilizando-se de colhedora TC59 (New Holland®), equipada com monitor de produtividade composto por sensor de fluxo e de umidade NH PLMS (AgLeader $\left.{ }^{\circledR}\right)$ e GPS Trimble ${ }^{\circledR}$ com correção por algoritmo interno, para aquisição dos dados referentes à colheita das áreas. As colheitas foram realizadas individualmente, colhendo-se primeiro as faixas referentes às doses fixas e posteriormente as faixas das doses variadas. Os mapas de produtividade, após tratamento preliminar de retirada dos valores discrepantes, foram obtidos pela interpolação dos dados utilizando o método do inverso da distância.

\section{RESULTADOS E DISCUSSÃO}

Analisando-se os resultados obtidos no experimento A, observa-se (Figura 1) que a produtividade média de milho das faixas onde se realizou a adubação em dose fixa, foi de $6.981 \mathrm{~kg} \mathrm{ha}{ }^{1}$, equivalente a $4 \%$ inferior àqueles das faixas referentes à adubação em doses variadas, que foi de $7.259 \mathrm{~kg} \mathrm{ha}^{-1}$, diferença significativa a $10 \%$ de probabilidade, pelo teste $\mathrm{t}$.

O conceito de unidades de gerenciamento subentende que todos os tratamentos sejam feitos uniformemente dentro de cada unidade, definida segundo a interação entre a oferta ambiental e a cultura em questão. Portanto, a aplicação de insumos por zonas definidas individualmente para cada um, com base em teores obtidos a partir de amostragem em grade, não pode ser confundida com unidades de gerenciamento e são então denominadas de unidades de aplicação. Nesse caso, no experimento A, a demanda total do fertilizante formulado em taxa fixa foi de $23.529 \mathrm{~kg}$, enquanto nas unidades de aplicação, segundo a recomendação do componente fósforo, o total demandado na mesma área foi de $20.242 \mathrm{~kg}$, ou seja, houve redução de 14\% (Figura 2). No entanto, se a aplicação em taxa variável fosse realizada de acordo com a recomendação de potássio, o consumo seria de $18.947 \mathrm{~kg}$ da fórmula em área total, o que reduziria em $6,4 \%$ o total aplicado quando comparado com aplicação variável de fósforo, razão que reforça a recomendação com base nos teores de fósforo. Nota-se, ainda, que em parte das áreas que apresentam teor de fósforo alto, os teores de potássio eram baixos (Figura 2). 
a

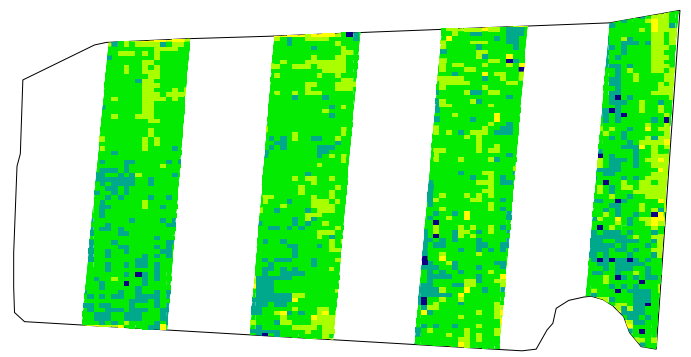

b

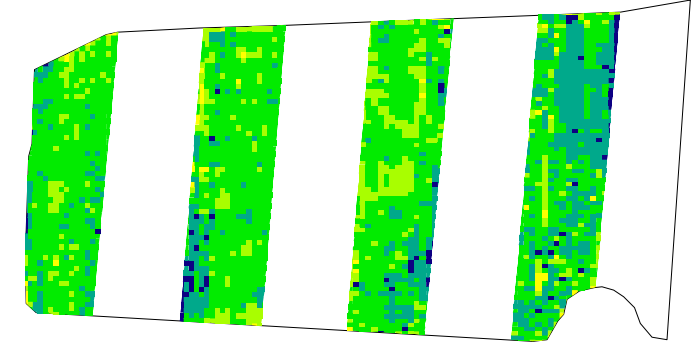

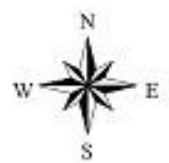

$100 \quad 100$ Meters

Produtividade $\left(\mathrm{kg} \mathrm{ha}^{-1}\right)$

$1000-5500$

$5500-6500$

$6500-7500$

$7500-8500$

$8500-12000$

FIGURA 1. Mapas de produtividade de milho referente ao experimento A, contendo as faixas referentes à dose fixa de adubação (a) e doses variadas (b).

a

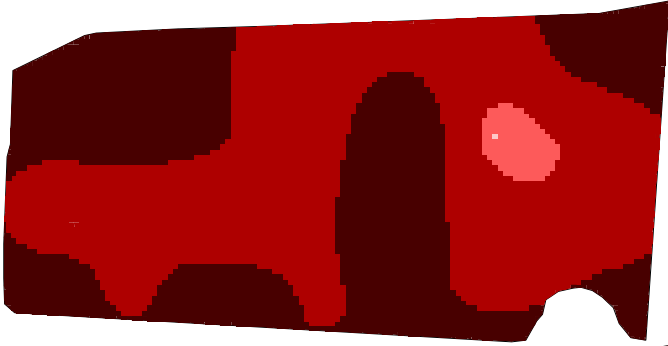

b

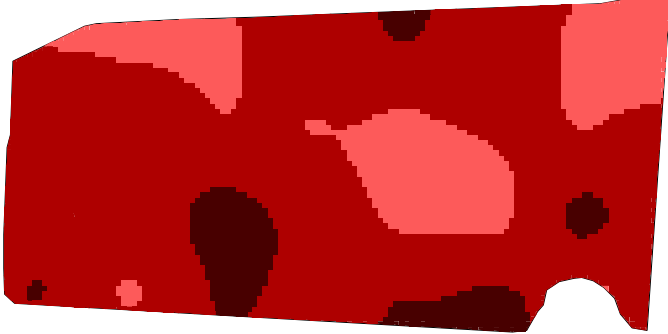

c

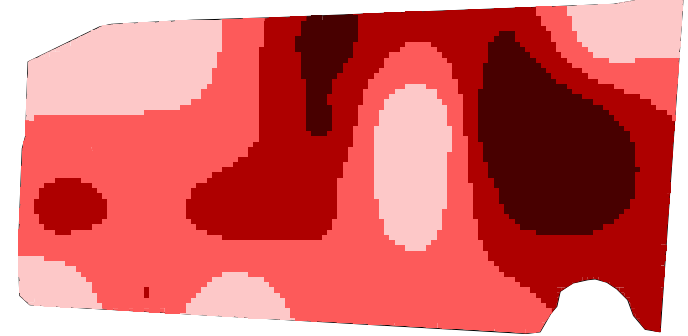

d

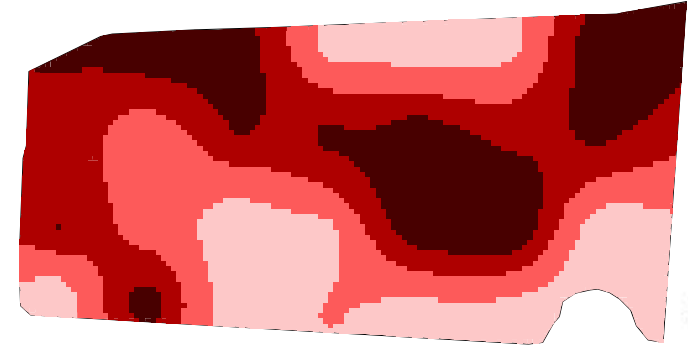

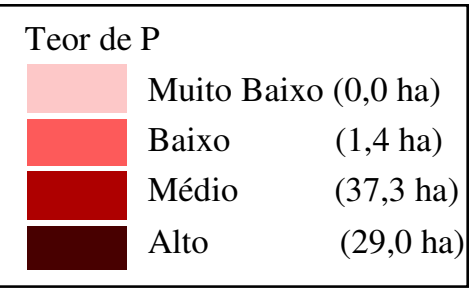

Teor de K

\begin{tabular}{|lr} 
Muito Baixo $(0,0 \mathrm{ha})$ \\
Baixo & $(14,0 \mathrm{ha})$ \\
Médio & $(47,0 \mathrm{ha})$ \\
\hline Alto & $(5,0 \mathrm{ha})$ \\
\hline
\end{tabular}

Recomendação de $\mathrm{P}\left(\mathrm{kg} \mathrm{ha}^{-1}\right)$

$\begin{array}{ll}41,6 & (14,1 \text { ha }) \\ 54,1 & (27,7 \mathrm{ha}) \\ 62,1 & (19,9 \text { ha }) \\ 74,0 & (9,7 \mathrm{ha})\end{array}$

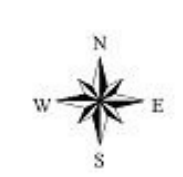

$100 \quad 100$ Meters

\begin{tabular}{|cc|}
\hline \multicolumn{3}{|c|}{ Recomendação de K $\left(\mathrm{kg} \mathrm{ha}^{-1}\right)$} \\
14,3 & $(16,3 \mathrm{ha})$ \\
39,4 & $(16,8 \mathrm{ha})$ \\
60,8 & $(21,7 \mathrm{ha})$ \\
84,8 & $(16,5 \mathrm{ha})$ \\
\hline
\end{tabular}

FIGURA 2. Mapa de teores de fósforo (a) e potássio (b) no solo a partir de análise de amostras em grade e mapas de recomendação de fósforo (c) e potássio (d) no experimento A (classes de teores no solo de acordo com IAC, 1997). 
Como a aplicação de fertilizante foi realizada de acordo com a recomendação de fósforo, foi possível gerar mapa demonstrando a diferença entre a quantidade aplicada e a requerida de potássio nas unidades de aplicação com doses variadas (Figura 3). As áreas onde se aplicou menos potássio que o requerido, representou 49,2\% do talhão e, na situação extrema, ocorreu acréscimo de $43,4 \mathrm{~kg} \mathrm{ha}^{-1}$ na dose de potássio, em $22,7 \%$ da área.

Assim como o potássio, o nitrogênio não foi considerado na elaboração da recomendação de aplicação do fertilizante, gerando diferenças espaciais na dose aplicada (Figura 3) em relação à dose requerida. Para evitar a deficiência deste nutriente na cultura, foi realizada aplicação de cobertura utilizando nitrato em taxa única de $150 \mathrm{~kg} \mathrm{ha}^{-1}$.

a
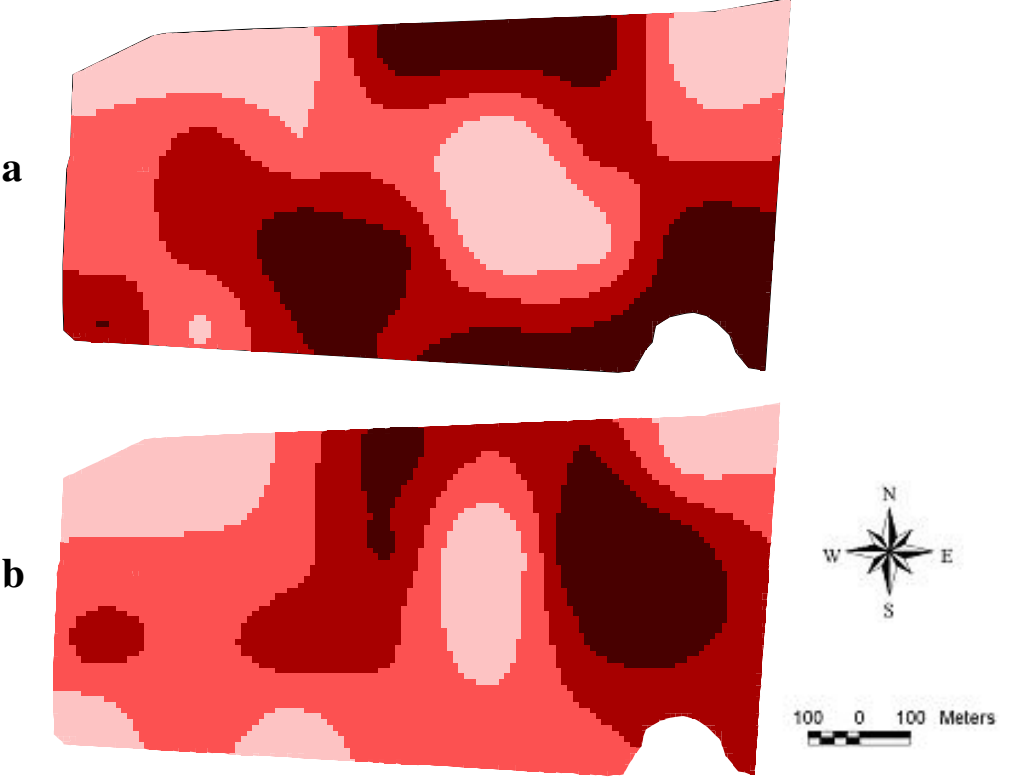

Diferença em K $\left(\mathrm{kg} \mathrm{ha}^{-1}\right)$

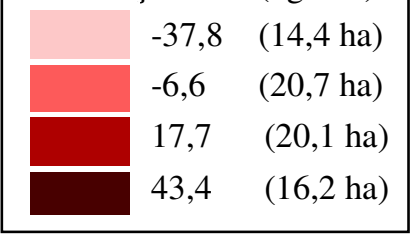

$\mathrm{N}$ Aplicado $\left(\mathrm{kg} \mathrm{ha}^{-1}\right)$

$16,5 \quad(14,0 \mathrm{ha})$

$21,6 \quad(28,2 \mathrm{ha})$

24,9 (19,7 ha)

$29,5 \quad(9,4$ ha $)$

FIGURA 3. Mapa de diferença de potássio entre a quantidade realmente aplicada e aquela recomendada a partir dos teores obtidos pela análise de amostras de solo em grade (a); mapa de nitrogênio aplicado na semeadura, em função do teor de $\mathrm{N}$ contido na fórmula do fertilizante (b) para o experimento A.

A produtividade média de milho na área do experimento $\mathrm{B}$, com a utilização de adubação em taxa fixa, foi de $7.425 \mathrm{~kg} \mathrm{ha}^{-1}$, enquanto, para a adubação em taxa variável, a produtividade média foi de $7.299 \mathrm{~kg} \mathrm{ha}^{-1}$, representando redução de $2 \%$ na produção (significativo a $10 \%$ de probabilidade, pelo teste t). Observa-se que os locais de elevada produtividade se mantiveram em ambos os sistemas de aplicação de fertilizantes (Figura 4), apresentando coeficiente de correlação $\left(\mathrm{r}^{2}\right)$ de $82,3 \%$, significativo a $5 \%$ de probabilidade, sugerindo problemas localizados de oferta ambiental, os quais devem ser investigados para futuras recomendações do gerenciamento agrícola do talhão.

O mapa de teor de fósforo do solo foi utilizado para gerar a recomendação de aplicação de fertilizante formulado, a exemplo do experimento anterior. No mapa que representa o teor de potássio do solo, pode-se observar que a maior parte da área $(95 \%)$ apresenta teor baixo do nutriente (Figura 5). A demanda para a aplicação da fórmula em taxa fixa foi de $5.280 \mathrm{~kg}$ e para a sua aplicação em taxa variável em relação ao fósforo foi de $5.840 \mathrm{~kg}$ (Figura 5), representando aumento de $11 \%$ na dose. A aplicação de fertilizante com base na necessidade de potássio seria de $7.387 \mathrm{~kg}$ e caso essa fosse utilizada resultaria em acréscimo de $26,4 \%$ ao recomendado com base na demanda de fósforo. 

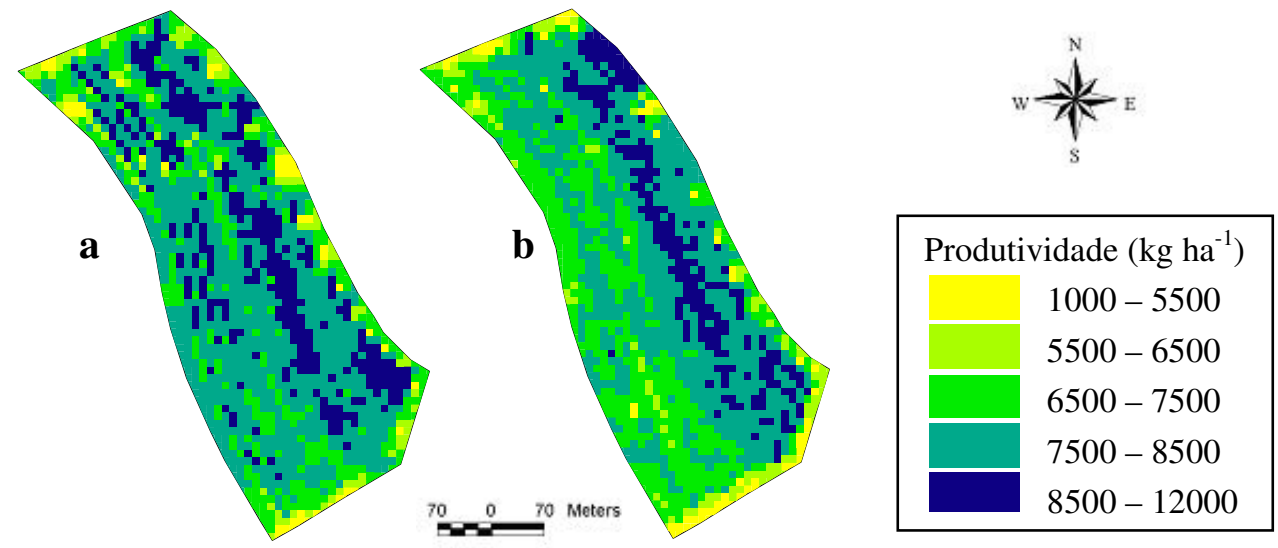

FIGURA 4. Mapas de produtividade de milho com dose de adubação fixa (a) e com dose variável (b), referente ao experimento B.

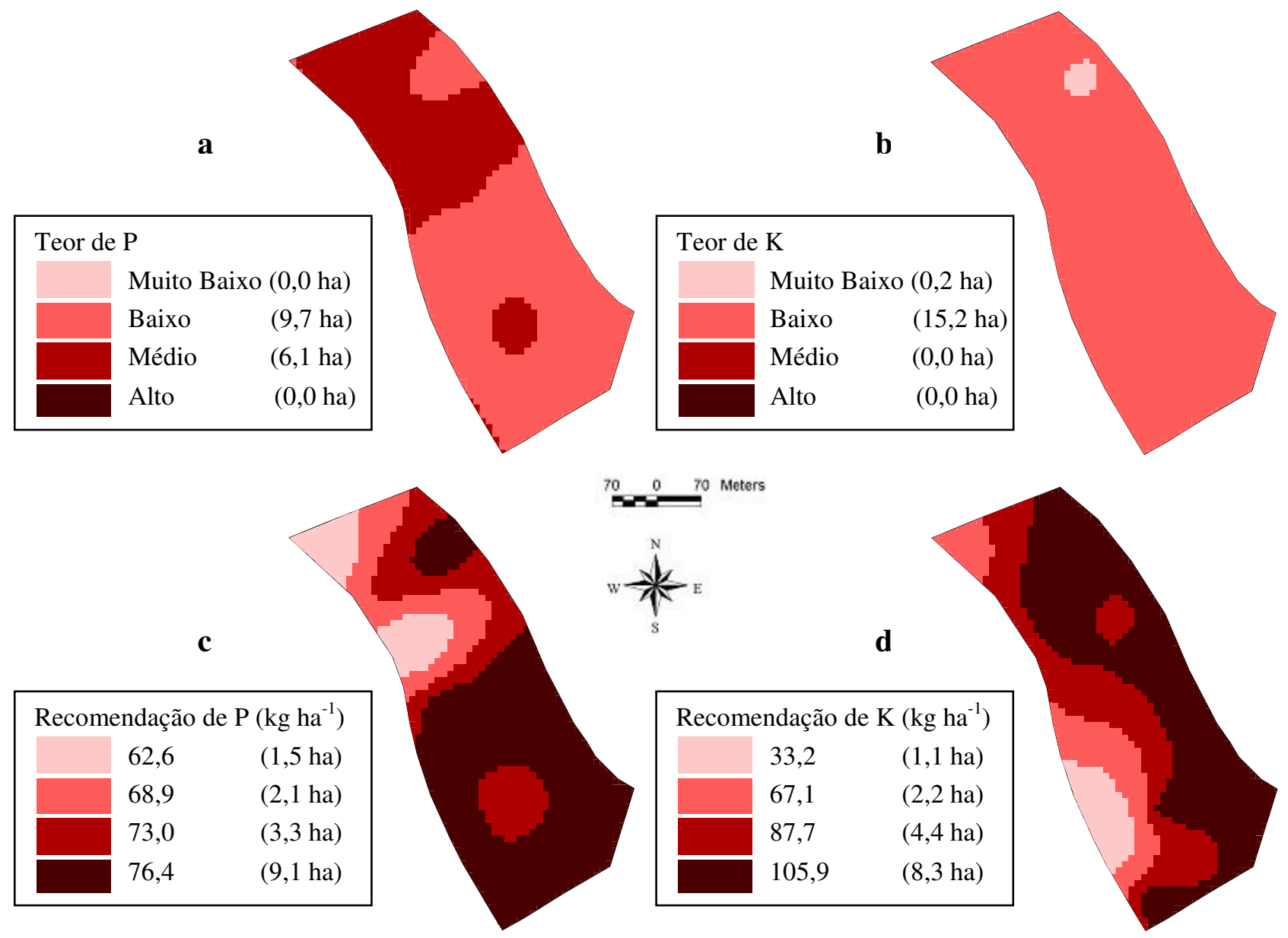

FIGURA 5. Mapas de teores de fósforo (a) e potássio (b) (classes de teores de acordo com IAC (1997); mapas de recomendação de fósforo (c) e de potássio (d) a partir dos teores obtidos pela análise de amostras de solo em grade, no experimento B.

O mapa da diferença entre a dose de potássio requerida e a aplicada, considerando-se a estratégia de aplicação em taxa variada da fórmula NPK (Figura 6), mostra que, em 85\% da área, aplicou-se menos quantidade do que o recomendado. É possível inferir ser esse o principal fator pela menor produtividade nas faixas com adubação variável. Entretanto, nessa inferência, há que se considerar outras limitações do gerenciamento adotado com relação à oferta ambiental, a exemplo das relações entre os nutrientes, as quais podem determinar a menor produtividade da cultura, independentemente da maior dose de potássio a ser aplicada. Em 5\% dessa área, ocorreu aplicação 
de doses elevadas de potássio, na ordem de $45,4 \mathrm{~kg} \mathrm{ha}^{-1}$ acima do que era exigido, o que também pode ter contribuído para menor produtividade nessas áreas em razão de possível desequilíbrio nas relações entre potássio e os demais elementos, notadamente nitrogênio. Portanto, há de se considerar a aplicação em dose variável de todos os nutrientes requeridos.

Como ocorrido no experimento A, parte do nitrogênio também foi aplicada de acordo com a recomendação de fósforo (Figura 6). A mesma estratégia e taxa de aplicação em cobertura de nitrato, adotados no experimento A, foram utilizadas neste experimento.

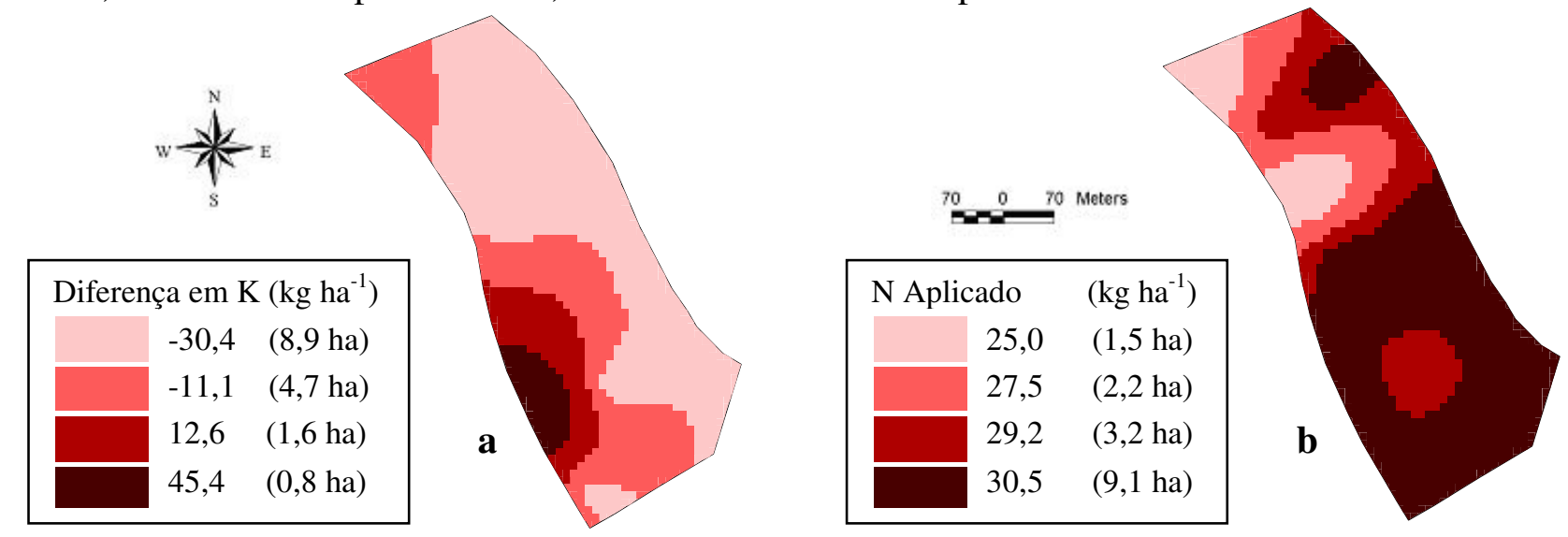

FIGURA 6. Mapa de diferença de doses de potássio entre a aplicada e aquela recomendada a partir dos teores obtidos pela análise de amostras de solo em grade (a); mapa de nitrogênio aplicado na semeadura em função do $\mathrm{N}$ contido na fórmula do fertilizante (b), no experimento $\mathrm{B}$.

A aplicação de sementes em doses variadas, nas unidades de aplicação referentes ao experimento $\mathrm{C}$ (Figura 7), foi superior em 2,6\% em relação à quantidade fixa, recomendada para $\mathrm{o}$ tipo de milho híbrido utilizado (60.000 sementes ha $\left.^{-1}\right)$. Em relação à influência da população e distribuição espacial de plantas sobre a produtividade de grãos, VIEIRA JUNIOR et al. (2004) verificaram nesse mesmo local que a população total de plantas contribui significativamente $(25,6 \%)$ para a redução na produtividade de grãos. Isso afeta aproximadamente $40 \%$ da produtividade dos grãos, sendo recomendada a determinação da população ideal, considerando diferentes ambientes e genótipos dentro de um mesmo sistema. As produtividades do experimento $\mathrm{C}$ foram de $6.152 \mathrm{~kg} \mathrm{ha}^{-1}$ para a dose fixa e $5.897 \mathrm{~kg} \mathrm{ha}^{-1}$ para a dose em taxa variável de sementes (Figura 7), apresentando redução de 4,2\% (significativa a $5 \%$ de probabilidade, pelo teste t), contrária ao resultado esperado. É possível inferir que as condições impostas no experimento, com altas e baixas populações de plantas, não foram adequadas ao híbrido utilizado. Essa inferência é possível ao considerar que a população máxima utilizada ficou aquém da provável população máxima requerida pelo híbrido, pois não houve redução na produtividade de grãos com a população máxima utilizada.

Observa-se que, com a utilização de população variável, houve área com maior produção, apresentando coeficiente de correlação $\left(\mathrm{r}^{2}\right)$ de $64,2 \%$, com a área onde se utilizou maior população. Já em $55 \%$ da área, adotaram-se populações abaixo do recomendado para a aplicação fixa; portanto, é possível inferir que a população mínima para o milho híbrido em questão é em torno de 60.000 sementes $\mathrm{ha}^{-1}$, podendo ser uma das causas da menor produtividade na área de população variável. Informações referentes a populações mínima e máxima recomendadas para o milho híbrido são uma carência verificada no mercado brasileiro de sementes.

O método de avaliação comparativa, com as semeadoras lado a lado, utilizado nos experimentos $\mathrm{B}$ e $\mathrm{C}$, é de grande valor, pois permite comparar os tratamentos com condições de oferta ambiental semelhantes. No entanto, exige controle rigoroso para separar os dois tratamentos referentes às faixas de semeadura, durante todo o processo de desenvolvimento da cultura, e 
principalmente na colheita individual dos tratamentos. A metodologia adotada no experimento A se mostrou mais simples e de fácil implantação devido às dimensões do talhão e da largura das faixas, mas deve-se considerar que, entre uma faixa e outra, podem ocorrer diferenças de oferta ambiental, o que pode afetar os resultados. Além disso, a representatividade das faixas deve ser muito bem equilibrada para a sua perfeita alocação no campo. Os resultados também podem ser afetados pelo controlador, em que a responsabilidade de mudança de posição em relação às unidades de aplicação é do operador, sendo recomendada a conexão do controlador a um receptor de GPS, que alteraria as doses automaticamente, dando assim maior confiabilidade ao experimento.

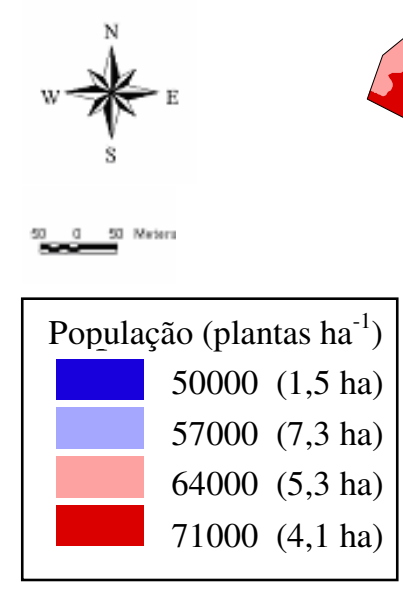

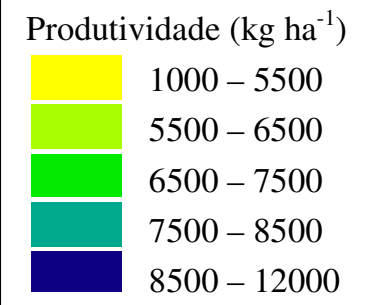

$8500-12000$

a

b

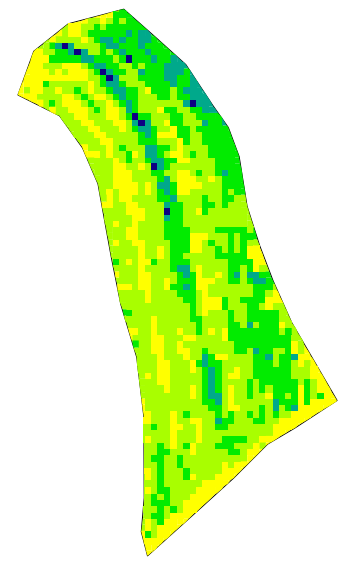

c

FIGURA 7. Mapa de recomendação de população de plantas de milho (a); mapas de produtividade com população variável de plantas (b) e população fixa (c), referentes ao experimento C.

Observa-se que o experimento A se apresentou coerente com a filosofia de gerenciamento por zonas, com produtividade sob taxa variada de aplicação de NPK maior que para a condição de taxa fixa, mesmo com uma pequena área ficando deficiente em potássio, o que aparenta não ter interferido significativamente na produção. Já para o experimento $\mathrm{B}$, o resultado foi oposto. Uma das possíveis causas foi que a área onde foi aplicado menos potássio que o recomendado, foi bastante significativa, o que, provavelmente, interferiu na produtividade de grãos devido à importância do potássio na fisiologia, notadamente quanto aos seus efeitos sobre o transporte celular e resistência a estresses ambientais. $\mathrm{O}$ sistema foi suprido de fósforo, o qual auxilia bastante na extração do potássio, podendo assim ter interferido na resposta de produção de milho. Por outro lado, o cloreto de potássio aplicado na semeadura em dose elevada (acima de $50 \mathrm{~kg} \mathrm{ha}^{-1}$ ) pode afetar significativamente a arquitetura da raiz (COELHO \& FRANÇA, 1995).

Devido a esses fatores, não é possível afirmar que a adubação em taxa variável, utilizando-se da fórmula NPK, foi eficiente devido à ambigüidade de resultados, o que indica a necessidade de trabalhar com a aplicação individualizada dos nutrientes que compõem o fertilizante. Isso implica considerarem-se máquinas equipadas com reservatórios e sistemas de controle individuais para os dois componentes básicos da adubação aqui considerados (fósforo e potássio) ou, no mínimo, utilizar critérios seguros para estabelecer a dose de fertilizante com base no elemento crítico.

\section{CONCLUSÕES}

A metodologia utilizada no experimento em faixas de $150 \mathrm{~m}$ de largura mostrou-se adequada em relação às características de formato regular e dimensão do talhão. O sistema de variação de doses de insumos mostrou-se eficiente, mas com confiabilidade totalmente dependente do operador.

A adubação em unidades de aplicação com taxas variáveis, utilizando fertilizante formulado NPK, mostrou-se ineficiente devido à recomendação de levar em conta apenas um nutriente afetando a produtividade da cultura. 
A adoção de população variável de plantas de milho resultou em maior quantidade de sementes e menor produtividade se comparada com a utilização de população uniforme.

\section{AGRADECIMENTOS}

Aos proprietários da Fazenda Velha Lagoa, local dos experimentos; às empresas Marchesan S.A. e Verion S.A., pela cessão dos equipamentos, e à New Holland Latin América, pela participação contínua nas atividades de pesquisa no local.

\section{REFERÊNCIAS}

BLACKMORE, S. Precision farming: an overview. Agricultural Engineering, St. Joseph, p.86-8, 1994.

CAMBOURIS, A.N.; NOLIN, M.C.; SIMARD, R.R. Optimisation of corn seeding rates based on clay content. INTERNATIONAL CONFERENCE ON PRECISION AGRICULTURE, 6., 2002, Minneapolis. Proceedings... Minneapolis: University of Minnesota, 2002. 1 CD-ROM.

COELHO, A.M.; FRANÇA, G.E. Seja o doutor do seu milho: nutrição e adubação. 2.ed. Piracicaba: Potafos, 1995. p.1-9. (Arquivo do Agrônomo, 8)

DOURADO NETO, D.; FANCELLI, A.L.; LOPES, P.P. Milho: população e distribuição de plantas. In: FANCELLI, A.L.; DOURADO NETO, D. (Ed.) Milho: tecnologia da produtividade. Piracicaba: ESALQ, 2001. p.120-5.

FRIDGEN, J.J.; KITCHEN, N.R.; SUDDUTH, K.A. Variability of soil and landscape attributes within sub-field management zones. INTERNATIONAL CONFERENCE ON PRECISION AGRICULTURE, 5., 2000, Minneapolis. Proceedings... Minneapolis: University of Minnesota, 2000. 1 CD-ROM.

GOERING, C.E.; HANS, S. A field information system for SSCM. In: INTERNATIONAL OFFHIGWAY \& POWERPLANT CONGRESS \& EXPOSITION, 1993, Milwaukee. Warrendale: SAE, 1993. 11 p. (SAE Technical Paper Series n. 932422).

IAC. Instituto Agronômico de Campinas. Recomendação de adubação e calagem para o Estado de São Paulo. 2. ed. Campinas, 1997. 295 p.

LOWENBERG-DEBOER, J. Economics of variable rate planting for corn. INTERNATIONAL CONFERENCE ON PRECISION AGRICULTURE, 4., 1998, St. Paul. Proceedings...

Minneapolis: P.C. Robert; R.H. Rust; W.E. Larson, 1998. p.1643-51.

SÁ, M.F.M. Abordagem quantitativa na predição espacial de atributos do solo e geração de zonas de manejo agrícola. 2001. 117 f. Tese (Doutorado) - Escola Superior de Agricultura "Luiz de Queiroz", Universidade de São Paulo, Piracicaba, 2001.

SHANAHAN, J.; DOERGE, T.; SNYDER, C.; LUCHIARI JUNIOR, A.; JOHNSON, J. Feasibility of variable rate management of corn hybrids and seeding rates. INTERNATIONAL CONFERENCE ON PRECISION AGRICULTURE, 5., 2000, Minneapolis. Proceedings... Minneapolis: University of Minnesota, 2000. 1 CD-ROM.

STEWART, C.M.; MCBRATNEY, A.B. Development of a methodology for the variable-rate application of fertilizer in irrigated cotton fields. INTERNATIONAL CONFERENCE ON PRECISION AGRICULTURE, 5., 2000, Minneapolis. Proceedings... Minneapolis: University of Minnesota, 2000. 1 CD-ROM.

VIEIRA JUNIOR, P.A.; MOLIN, J.P.; DOURADO NETO, D.; MANFRON, P.; MASCARIN, L.S.; FAULIN, G.C.; DETOMINI, E.R. Relação entre população, distribuição espacial de plantas, atributos do solo e rendimento de grãos de milho. CONGRESSO BRASILEIRO DE

AGRICULTURA DE PRECISÃO, 1., 2004, Piracicaba. Anais... Piracicaba: Escola Superior de agricultura "Luiz de Queiroz”, Universidade de São Paulo, 2004. 1 CD-ROM. 